\title{
Breeding-Site Selection By Ferruginous Hawks Within Utah's Uintah Basin
}

\author{
Author(s): Heather L. Keough and Michael R. Conover
}

Source: Journal of Raptor Research, 46(4):378-388.

Published By: The Raptor Research Foundation

DOI: http://dx.doi.org/10.3356/JRR-12-07.1

URL: http://www.bioone.org/doi/full/10.3356/JRR-12-07.1

BioOne (www.bioone.org) is a nonprofit, online aggregation of core research in the biological, ecological, and environmental sciences. BioOne provides a sustainable online platform for over 170 journals and books published by nonprofit societies, associations, museums, institutions, and presses.

Your use of this PDF, the BioOne Web site, and all posted and associated content indicates your acceptance of BioOne's Terms of Use, available at www.bioone.org/ page/terms_of_use.

Usage of BioOne content is strictly limited to personal, educational, and noncommercial use. Commercial inquiries or rights and permissions requests should be directed to the individual publisher as copyright holder. 


\title{
BREEDING-SITE SELECTION BY FERRUGINOUS HAWKS WITHIN UTAH'S UINTAH BASIN
}

\author{
Heather L. Keough and Michael R. Conover ${ }^{1}$ \\ Department of Wildland Resources, Utah State University, Logan, UT 84322 U.S.A.
}

\begin{abstract}
We examined factors that might influence breeding-site selection in Ferruginous Hawks (Buteo regalis) in the Uintah Basin, Utah, an area undergoing rapid oil and gas development. We located 31 occupied nests of Ferruginous Hawk (10 during 2002, 10 during 2003, and 11 during 2004) and compared them to 32 historical nest sites of Ferruginous Hawks that were unoccupied during our study, and 32 random sites. Ferruginous Hawks selected nesting areas that were dominated by mixed desert-shrub vegetation communities with scattered Utah juniper trees (Juniperus osteosperma), higher prey abundance, and a high number of active petroleum wells. Within occupied territories, Ferruginous Hawks selected nest sites in juniper trees, on cliff ledges, or on rock pinnacles that occurred in areas with higher prey abundance, close to an active well, and within $2-3.5 \mathrm{~km}$ of the nearest occupied nest of another raptor. The counterintuitive association between nesting activity and oil development may be the result of: (1) a spurious relationship between the occurrence of oil and gas reserves and suitable breeding habitat, (2) a time lag in the response of nesting pairs to development, or (3) oil and gas developments indirectly benefiting nesting pairs by improving the habitat of prey species and subsequently increasing prey densities, and/or reducing the threat of predation to Ferruginous Hawks or their young.
\end{abstract}

KeY Words: Ferruginous Hawk; Buteo regalis; habitat selection; landscape ecology; nest-site selection; Utah.

\section{SELECCIÓN DEL SITIO DE NIDIFICACIÓN DE BUTEO REGALIS EN LA CUENCA DE UINTAH, UTAH, ESTADOS UNIDOS}

\begin{abstract}
RESUMEN.-Examinamos los factores que pueden influir en la selección de sitios de nidificación en Buteo regalis en la cuenca de Uintah, Utah, un área que está experimentando un rápido desarrollo de combustibles y gas. Ubicamos 31 nidos ocupados por B. regalis (10 durante 2002, 10 durante 2003 y 11 durante 2004) y los comparamos con 32 sitios de nidificación históricos de la misma especie que estuvieron desocupados durante nuestro estudio y con 32 sitios al azar. Los individuos de $B$. regalis seleccionaron áreas de nidificación que estuvieron dominadas por una mezcla de comunidades vegetales arbustivas xerófilas con árboles de Juniperus osteosperma, por una mayor abundancia de presas y por un elevado número de pozos petroleros activos. Dentro de los territorios ocupados, los individuos de B. regalis seleccionaron los sitios de nidificación en árboles de $J$. osteosperma, en bordes de acantilados o en pináculos de roca que se encontraban en áreas con mayor abundancia de presas, cerca de un pozo petrolero activo y dentro de los 2-3.5 km del nido más cercano ocupado por otra rapaz. La asociación contra intuitiva entre la actividad de nidificación y el desarrollo petrolero puede ser el resultado de (1) una relación dudosa entre la ocurrencia de reservas de combustible y gas y un hábitat apropiado, (2) un retraso en el tiempo de respuesta de las parejas reproductivas al desarrollo o (3) que el desarrollo de combustibles y gas beneficie indirectamente a las parejas reproductivas al mejorar el hábitat de especies presa y subsecuentemente aumentando las densidades de presa y/o al reducir las amenazas de depredación de individuos de B. regalis o de sus pichones.
\end{abstract}

[Traducción del equipo editorial]

The breeding population of Ferruginous Hawks (Buteo regalis) in Utah's Uintah Basin has declined over the last two decades (Keough 2006). Human disturbance of nesting habitat has been suggested as a contributing factor to the decline in Ferruginous

\footnotetext{
1 Email address: mike.conover@usu.edu
}

Hawk populations (Olendorff 1993, Zelenak and Rotella 1997, Keeley and Bechard 2011). Primary effects of human disturbance include decreased reproductive performance, direct mortality, and habitat alteration that decreases prey abundance (Smith and Murphy 1978, Gilmer and Stewart 1983, White and Thurow 1985, Olendorff 1993). 
During the breeding season, Ferruginous Hawks are sensitive to human disturbance, particularly during nest-site selection, courtship, and incubation; even mild disturbance can lead to nest abandonment during these critical time periods (Bechard et al. 1990, Leslie 1992, Olendorff 1993, Dechant et al. 2003, Keeley and Bechard 2011).

Many new oil and gas well developments in the Uintah Basin are located in Ferruginous Hawk nesting habitat. These developments result in habitat alteration, road construction, and increased recreational use (Olendorff 1993). Although studies in Montana (Van Horn 1993, Zelenak and Rotella 1997) revealed no statistically significant relationship between Ferruginous Hawk reproductive success and oil and gas well development, the influence of oil and gas well development on the reproductive success of Ferruginous Hawks in the Uintah Basin is unknown. Thus it seemed prudent to examine factors that may influence breeding-site selection, including oil and gas well development.

For most avian predators, prey availability and competition for space influence breeding-site selection. The same is likely true for Ferruginous Hawks. They prey primarily on ground squirrels (Spermophilus spp.), pocket gophers (Thomomys spp.), prairie dogs (Cynomys spp.), and jackrabbits (Lepus spp.; Bechard and Schmutz 1995, Rosamonde et al. 2003, Dechant et al. 2003, Giovanni et al. 2007). Ferruginous Hawk nesting density and nest success are closely related to prey abundance and availability (Zelenak and Rotella 1997, Ward 2001, Dechant et al. 2003, Schmutz et al. 2008, Keeley 2009). Ferruginous Hawks demonstrate intraspecific competition for space (Schmutz and Hungle 1989). They nest sympatrically with Redtailed Hawks (Buteo jamaicensis) and Swainson's Hawks (Buteo swainsoni), but reproductive success of these three species declines when they nest in close proximity (Schmutz et al. 1980). Ferruginous Hawks nesting farther from nests of other breeding raptor pairs produce more young, suggesting that reproductive success may be negatively influenced by competition (Zelenak and Rotella 1997).

Based on the literature and our experience, we hypothesized that the primary factors influencing Ferruginous Hawk breeding-site selection include: (1) dominant land-cover type, (2) prey abundance, (3) presence of other occupied raptor nests, (4) nesting substrate, and (5) presence of active petroleum wells. In this study, we tested these hypotheses by comparing Ferruginous Hawk nests in the Uintah Basin to unused sites.

\section{StUdy AREA}

Our study was conducted on a $2365-\mathrm{km}^{2}$ area in the Uintah Basin in eastern Utah, managed by the Bureau of Land Management (BLM) Vernal Field Office (Fig. 1). During the three years prior to our study, $>90 \%$ of Ferruginous Hawks breeding in the Uintah Basin nested within our study area, based on aerial and ground surveys conducted by the BLM. The 28 205-km² Uintah Basin lies at approx. $1500 \mathrm{~m}$ asl and is part of the Colorado Plateau. The climate is semiarid with low humidity. The study area is divided into two vegetation zones by the Green River due to regional differences in precipitation, with shrub-grass on the west side and a mixture of shrub-grass and Utah juniper trees (Juniperus osteosperma) on the east side. Utah juniper trees were the only tree species growing in most of our study area.

\section{METHODS}

We conducted our study during the three breeding seasons of 2002-04, a time when high petroleum prices caused an increase in oil development in our study area. Oil development in the Uintah Basin has occurred for many decades, and we lack data on breeding-site selection by Ferruginous Hawks prior to oil development. For this reason, we used a gradient design to study the response of Ferruginous Hawk breeding-site selection to various levels of oil and gas well development. A gradient design is one of several options for evaluating effects of disturbances in a suboptimal "after-only" design (Morrison et al. 2001). Gradient designs analyze an effect along a continuous scale and statistically test for an association between level of effect and response by the animal. When using a gradient design, one must assume that the complete or nearly complete range of effects has been sampled evenly to ensure analyses are robust. In addition, sampling across the complete range of effects increases the likelihood that the natural stochasticity in the environment is balanced across samples and differences are due to the disturbance. Although we had no control over the placement of occupied Ferruginous Hawk nests relative to oil and gas well development, we believe that the complete or nearly complete range of effects was represented, because nest sites were located at variable distances from development, different nesting pairs demonstrated variable sensitivities to human disturbance, and sampling occurred over three breeding seasons.

Identifying Occupied Nest Sites, Unoccupied Historical Nest Sites, and Random Sites. In our study 


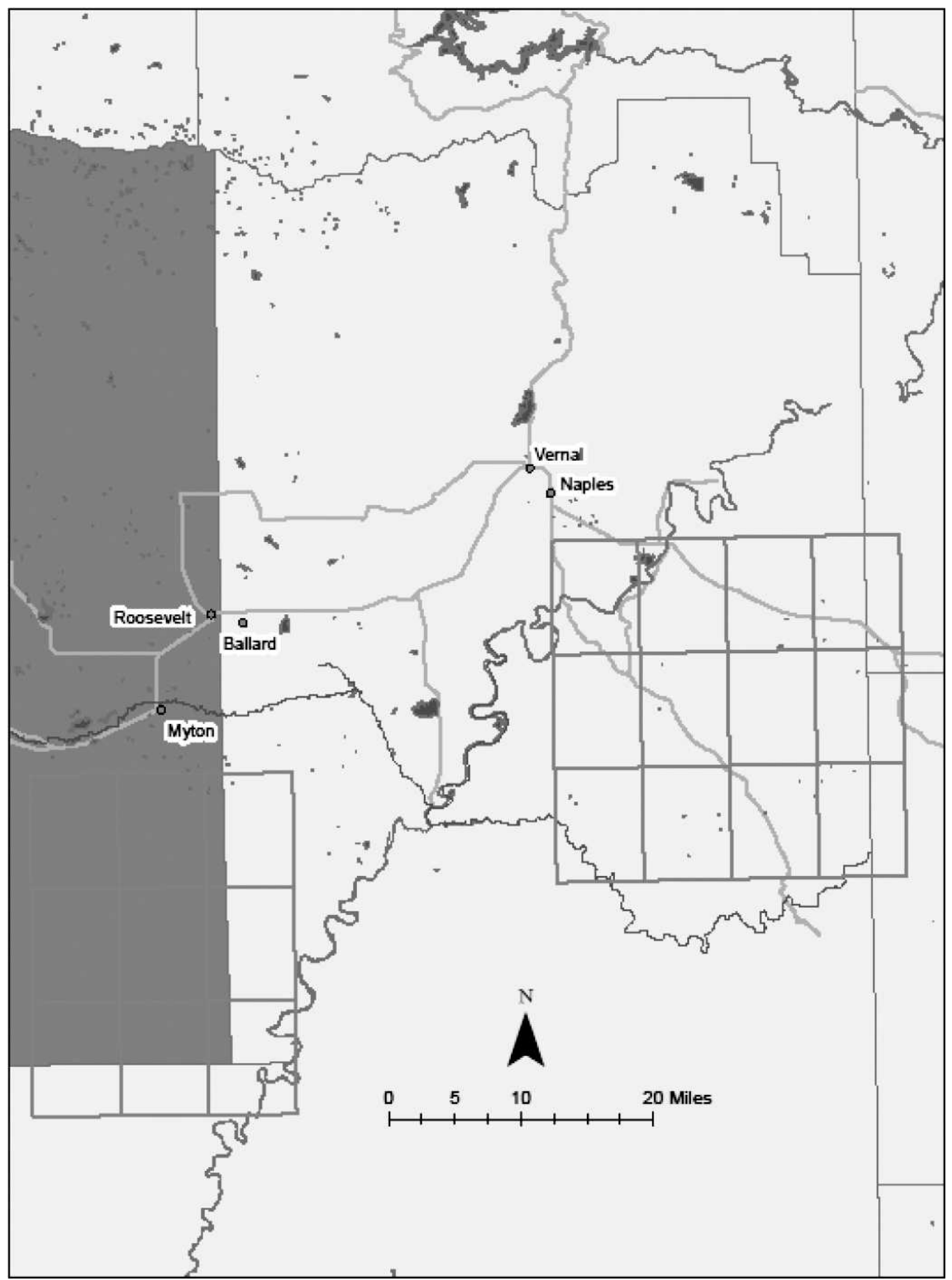

Figure 1. Our 2365-km² study area within Utah's Uintah Basin, Utah, included 16 7.5-min quadrangle maps which are shown as rectangles on the map (each rectangle is $10.5 \mathrm{~km}$ wide and $14 \mathrm{~km}$ high). These maps included: Crow Knoll, Myton SW, Myton SE, Pariette Draw SW, Wilkin Ridge, Red Wash SE, Red Wash SW, Bonanza, Walsh Knolls, Dinosaur, Dinosaur NW, Red Wash, Red Wash NW, Cliff Ridge, Jensen, and Rasmussen Hollow. Active oil and gas wells are shown as black spots. 
area, an abandoned raptor nest can persist for decades. Most Ferruginous Hawks select one of these historical nest structures and build their own nest on top of it. For this reason, we compared historical nest sites that Ferruginous Hawks used for breeding during our study (occupied nest sites) to historical nest sites that were not used for nesting (unoccupied historical nest sites). BLM Vernal Field Office maintained an ArcView database of dozens of historical raptor nest structures within our study area. During May and June from 1998 until 2002, BLM checked these historical nest sites for nesting activity from the ground or air and added any new nests to the database as they were located. During May and June, 2002-04, we surveyed all Ferruginous Hawk nest sites that were occupied during any of the $4 \mathrm{yr}$ preceding our study. We surveyed these nests via foot or vehicle to evaluate nesting activity. All observations were made using binoculars and/or a spotting scope from a distance of $>250 \mathrm{~m}$ to minimize human disturbance and the risk of site abandonment (Fyfe and Olendorff 1976).

Between late-May and early-June, 2002-04, we also surveyed our study area for occupied nest sites by flying transects for $>20 \mathrm{hr}$ annually using a fixedwing aircraft following the method of Ayers and Anderson (1999). Flight plans were based on the location of historical nest sites of Ferruginous Hawks and randomly selected coordinates so that we could detect any Ferruginous Hawks that nested somewhere other than at a historical nest site. To maximize detectability and minimize potential disturbance to nesting Ferruginous Hawks, transects were flown at an average speed of $145 \mathrm{~km} / \mathrm{hr}$ and at a minimum height of $60 \mathrm{~m}$. A single-pass technique was used where the aircraft did not deviate from transects unless observers needed to confirm nest observations (Ayers and Anderson 1999). We believe that we found all occupied Ferruginous Hawk nests in our study area due to our intensive search effort, the openness of the desert habitat, the conspicuousness of Ferruginous Hawk nests when seen from above during an aerial survey, and the conspicuousness of soaring Ferruginous Hawks.

Nests were recorded as occupied if we observed: (1) an adult incubating or demonstrating defensive behavior, (2) a pair of adults in the area consistently, or (3) eggs or hatchlings in a nest. Defensive behavior included stooping and circling over the nest site or observer and vocalizing. Each season, after we completed surveys for occupied nests of Ferruginous Hawks, we randomly selected unoccupied historical nest sites of Ferruginous Hawk from the BLM dataset. Using ArcView, we annually selected unoccupied historical nest sites by (1) mapping occupied nests sites of Ferruginous Hawk, (2) randomly selecting 10-12 unoccupied historical nest sites that were $>4 \mathrm{~km}$ from occupied nests or other selected unoccupied historical nest sites.

Because vegetation differed on the east and west sides of the Green River, we selected unoccupied historical sites and random sites so they were proportionally distributed on both sides of the Green River. Between 1998 and 2000, approximately 80\% of Ferruginous Hawks nested east of the Green River. Hence, unoccupied historical nest sites and random sites were selected each season so that $75-80 \%$ of each category occurred on the east side of the study area and 20-25\% occurred on the west side.

Average home range estimates for Ferruginous Hawks were $6 \mathrm{~km}^{2}$ (Smith and Murphy 1978), $7 \mathrm{~km}^{2}$ (Olendorff 1993), and $90 \mathrm{~km}^{2}$ (Leary et al. 1998). The average for these three reported average home-range sizes was approximately $35 \mathrm{~km}^{2}$. To ensure that we included the entire breeding home range for nesting Ferruginous Hawk pairs in the assessment of prey resources and competitive interactions, we collected data within a $4-\mathrm{km}$ radius $\left(50 \mathrm{~km}^{2}\right)$ around each occupied nest site, unoccupied historical nest site, and random site (hereafter we refer to these collectively as sample sites).

Potential Factors Influencing Breeding-site Selection. In our study area, Ferruginous Hawk nests were located on five substrates: ground, cliff ledge, rock pinnacle, juniper tree, and human-made structures. Hence, we classified all occupied nest sites and unoccupied historical nest sites into one of these categories (Table 1). We determined the two most dominant land-cover types occurring within $4 \mathrm{~km}$ of each site using ArcView and land-cover data for Uintah and Duchesne counties provided by the USGS National Gap Analysis Program (2004). In almost all cases, the area made up by the two most dominant land-cover types represented $>60 \%$ of the $50-\mathrm{km}^{2}$ area around each site. Based on the resulting combinations, we defined six common categories of dominant land-cover types: (1) barren (e.g., bedrock canyon and tablelands, or shale badlands); (2) mixture of sagebrush (Artemisia spp.) shrubland and salt desert scrub; (3) sagebrush shrubland only; (4) mixture of barren and sagebrush shrubland, barren and saltbush (Atriplex spp.) shrubland, or barren and salt desert scrub; (5) mixture of grassland and salt desert scrub, 
Table 1. Abbreviations for the ten potential explanatory variables used in classification tree analysis to differentiate occupied Ferruginous Hawk nest sites, unoccupied historical Ferruginous Hawk nest sites, and random sites where there was no evidence of prior nesting by Ferruginous Hawks, located within the Uintah Basin, eastern Utah, during three breeding seasons (2002-04).

EXPLANATORY VARIABLE

Nesting substrate

Dominant land-cover type within $4 \mathrm{~km}$ radius of each site

Total number of white-tailed prairie dogs seen during line-transects

Total number of lagomorphs seen during line-transects Total number of lagomorphs seen during road-transects Distance in $m$ to closest other occupied raptor nest

Total number of raptors seen while conducting line-transects

Number of other occupied raptor nests within 1-, 1.5-, 2-, 2.5-, 3-, 3.5-, and 4-km radii of each site

Distance in $\mathrm{m}$ to closest active well

Number of active wells within 1-, 1.5-, 2-, 2.5-, 3-, 3.5-, and $4-\mathrm{km}$ radii of each site
ABBREVIATION

NEST_SUB $=$ GROU, LEDG, PINN, JUNI, or MAN

COVER $=$ B, SSC, S, BS, SBG, or SJ

NO_PDLINT

NO_LGLINT

NO_LGRDT

DIS_NRRAP

NO_RAPLNT

CNTR_4000, CNTR_3500, CNTR_3000, CNTR_2500,

CNTR_2000, CNTR_1500, and CNTR_1000

DIS_NRWEL

CNTW_4000, CNTW_3500, CNTW_3000, CNTW_2500, CNTW_2000, CNTW_1500, and CNTW_1000 grassland and barren, or grassland and sagebrush shrubland; and (6) mixture of sagebrush shrubland and pinyon-(Pinus spp.) juniper shrubland or pinyon-juniper woodland (Table 1). According to the land-cover descriptions provided for the USGS National Gap Analysis Program (2004), scattered juniper may be found in sagebrush shrubland, mixed salt desert scrub, or pinyon-juniper shrubland land-cover types.

Ferruginous Hawks in the Uinta Basin preyed mainly on white-tailed prairie dogs (Cynomys leucurus), black-tailed jackrabbits (Lepus californicus), and desert cottontails (Sylvilagus audubonii; Stalmaster 1988). When Ferruginous Hawks search for food, only prey aboveground are available for capture. Thus, we used a line-transect sampling method that estimated prey numbers by focusing on prey species observed aboveground. To obtain a relative measure of prey abundance, we used a consistent method and sampling effort for all surveys. Around each sample site, we centered a $2-\mathrm{km}$ by 2 -km square, with a 1-km line-transect arranged along each side. This arrangement placed all line-transects $\geq 1 \mathrm{~km}$ from each site to minimize disturbance to nesting pairs. During the three breeding seasons, we walked clockwise along each line-transect between 0700 and $1300 \mathrm{H}$ and recorded the number of whitetailed prairie dogs, black-tailed jackrabbits, and desert cottontails that we observed around each study site.

During the 2003 and 2004 breeding season, we also conducted road-based nocturnal surveys as an additional index to lagomorph abundance at each study site. Using ArcView, we randomly selected two points that were $<4 \mathrm{~km}$ from each study site and $>3 \mathrm{~km}$ apart. The closest point on a good road (e.g., graded roads, paved roads, and frequently used two-tracks) nearest to the random point was used as a starting point. Beginning at the selected starting points, two 2-km road-transects were established for each site. The direction of road-transects was selected systematically to ensure all transects occurred within $4 \mathrm{~km}$ of each site and that any overlap among transects was minimized. We drove approximately $8 \mathrm{~km} / \mathrm{hr}$ from 2100-2300 H along the road-transects. Using the illumination provided by the vehicle's headlights, we recorded the number of black-tailed jackrabbits and desert cottontails observed during each transect. All line-transects and road-transects were sampled once between late May and late June and once between early July and early August. We calculated for each sample site the total number of white-tailed prairie dogs and lagomorphs seen during line-transects and road-transects and used these values as indices of prey availability.

During June and July, 2002-04, we searched via foot and airplane for any raptors nesting within $4 \mathrm{~km}$ of each sample site. We used ArcView to measure the distance from each sample site to the nearest occupied raptor nest occupied by Ferruginous Hawks, Red-tailed Hawks (Buteo jamaicensis) Golden Eagles (Aquila chrysaetos), Prairie Falcons (Falco mexicanus), or Great Horned Owls (Bubo virginianus). We counted the number of occupied raptor nests 
that occurred within 1-, 1.5-, 2-, 2.5-, 3-, 3.5-, and 4-km radii of each sample site. We also recorded the number of raptors observed during each line-transect prey survey as a measure of raptor activity. We calculated for each sample site the total number of raptors seen during all line-transects around that site.

The BLM supplied an ArcView database that included well type and status listings for all oil and gas well developments in the study area (Bureau of Land Management 2005). In collaboration with the BLM Vernal Field Office, we categorized these data into active and inactive wells based on associated human activity levels. The active categories included: active drilling, producing gas well, producing oil well, water disposal well, water disposal well shut-in, water injection well, water injection well shut-in, water source well, and water source well shut-in. Using ArcView, we measured the distance from each sample site to the nearest active well and counted the number of active wells that occurred within 1-, 1.5-, 2-, 2.5-, 3-, 3.5-, and 4-km radii of each sample site (Table 1).

Statistical Analysis. We selected different random sites and unoccupied historical sites each year and compared them to all occupied nests that occurred within our study area during the same year. We considered all random sites, unoccupied historical nest sites, and occupied nest sites collected in different years to be independent data points, although five nests were occupied in two different years and data from both years were included in our study. We did not band adult Ferruginous Hawks and could not confirm whether the same hawks nested in multiple years. Data from all years were combined for all analyses.

We used classification and discriminant analyses to determine which of the ten measured variables best differentiated between occupied nest sites and unoccupied historical nest sites to address the question of why Ferruginous Hawks occupied particular historical nest sites. We also used the same analyses to compare occupied nest sites to random sites. Because we have categorical response variables, a mixture of continuous and categorical explanatory variables, missing data values (e.g., road surveys were not conducted in 2002), and relationships between variables that are likely to be nonlinear or involve high-order interactions, we analyzed our data with classification trees due to their suitability for analyzing such data (De'ath and Fabricius 2000).

We considered two classification trees: one model differentiated between occupied nest sites and unoccupied historical nest sites, and a second model differentiated between occupied nest sites and random sites. Explanatory variables were not transformed; they were used as defined in the methods. We omitted nesting substrate from the classification tree differentiating occupied nest sites and random sites because random sites did not contain an actual nest.

For each classification tree, we ran 50 10-fold cross-validations and selected the most frequently occurring tree size using the minimum cross-validated-error rule (De'ath and Fabricius 2000). The models selected by cross-validation can be interpreted as the trees which had the smallest estimated true (prediction) error and were the best estimated predictive trees (De'ath and Fabricius 2000).

All analyses were run using the Mvpart Package Version 1.0-1 (De'ath 2004) in R Version 2.1.0 using cross-validation method $\mathrm{xv}=$ "pick," complexity parameter $\mathrm{cp}=0.001$, and the remaining default settings (R Development Core Team 2005). Once the two best trees were selected, we used the models to predict the class of each observation. We then calculated the rate of correct classification by the following equation: (the number of observations classified correctly - number of observations classified incorrectly) $\div$ the total number of observations. We defined the rate of incorrect classification as 1 - the rate of correct classification. We also calculated the percentage of occupied sites misclassified as unoccupied or random as (the number of occupied sites classified as unoccupied historical sites and/or random sites $) \div$ the total number of occupied sites.

\section{RESUlts}

During the three breeding seasons, we located 31 occupied nests of Ferruginous Hawks (10 during 2002, 10 during 2003, and 11 during 2004) and compared them to 32 unoccupied historical nest sites and 32 random sites (12 of each during 2002, 10 during 2003, and 10 during 2004). Five nests were used during multiple years; one nest that was occupied during 2002 was also occupied during 2004, and four occupied nests during 2003 were also occupied during 2004. All these nests were included in our study, and we acknowledge some potential nonindependence associated with these sites. We located 71 occupied nests of other raptor species that were larger than an American Kestrel (Falco sparverius): 40 Red-tailed Hawk nests (12 in 2002, 11 in 2003, and 17 in 2004); 22 Golden Eagle nests (3 in 2002, 7 in 2003, and 12 in 2004); 8 


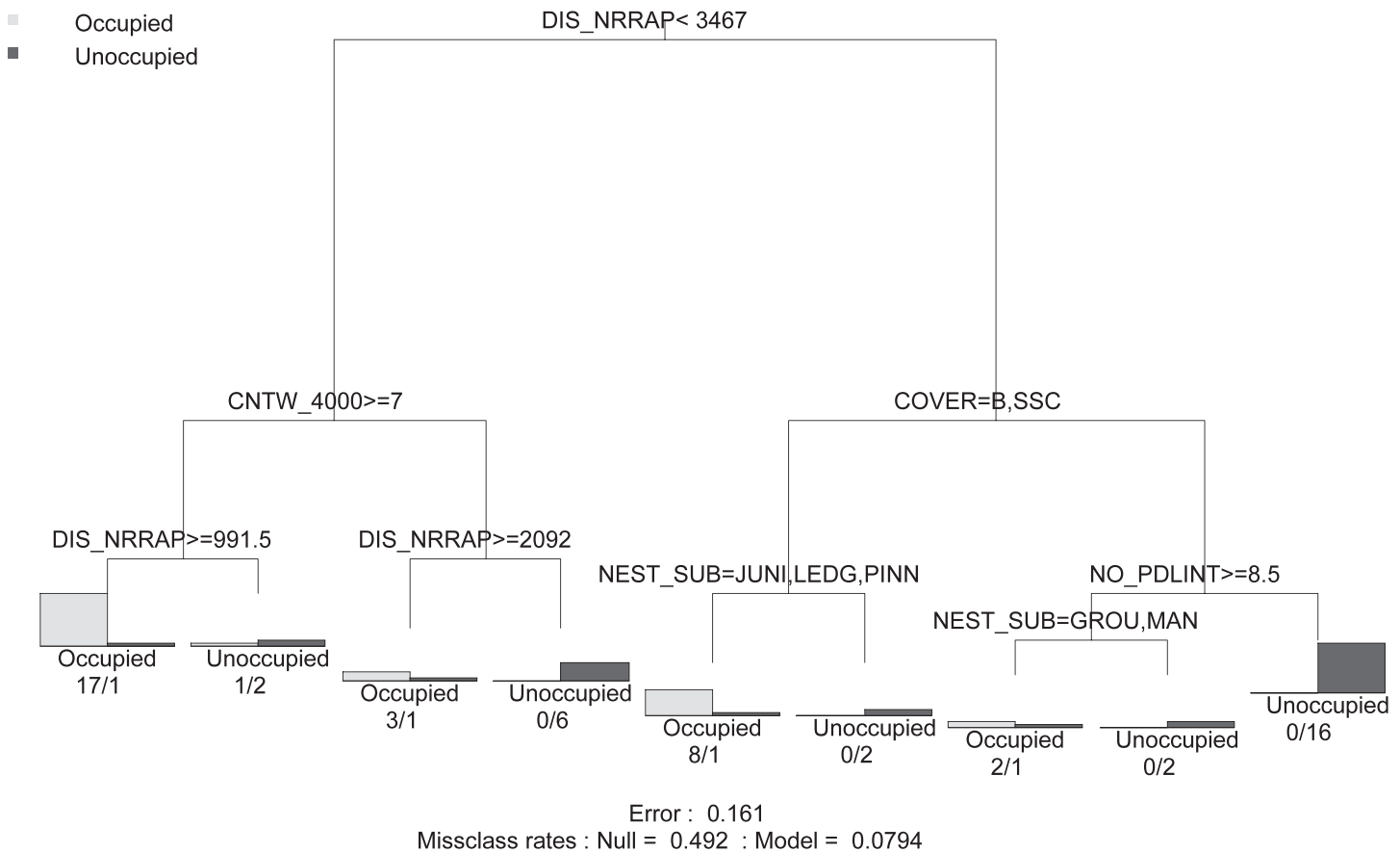

Figure 2. Best classification tree differentiating occupied nest sites and unoccupied historical nest sites of Ferruginous Hawks, located within the Uintah Basin, eastern Utah, during three breeding seasons (2002-04). Each of the eight splits is labeled with the explanatory variable that determined the split and its values for sites split to the left (see Table 1 for a definition of abbreviations). For each of the nine leaves, the distribution of the observed classes is shown in a histogram.

Prairie Falcon nests (one in 2002, two in 2003, and five in 2004); and one Great Horned Owl nest in 2004.

The best classification tree differentiating occupied nest sites and unoccupied historical nest sites of Ferruginous Hawks included nine leaves (Fig. 2). Explanatory variables that determined the eight splits were distance to the closest occupied raptor nest, number of active wells within a $4-\mathrm{km}$ radius of each site, dominant land-cover type, nesting substrate, and number of prairie dogs seen during line-transects. Being classified as an occupied nest site was associated with: (1) sites occurring between 991 and $3467 \mathrm{~m}$ from the closest occupied raptor nest; (2) areas with high numbers $(\geq 7)$ of active wells within a 4-km radius of sites; (3) areas dominated by bedrock canyon and tablelands, shale badlands, or a mixture of sagebrush shrubland and salt desert scrub; (4) nests located in juniper trees, on cliff ledges, on rock pinnacles; and (5) areas with high numbers of prairie dogs.

The best tree differentiating occupied nest sites and random sites included ten leaves (Fig. 3). The explanatory variables that determined the nine splits in the tree included dominant land-cover type, distance to the closest active well, total number of lagomorphs seen during line-transects, number of active wells within a $4-\mathrm{km}$ or $1.5-\mathrm{km}$ radius of each site, number of prairie dogs seen during line-transects, and number of raptors seen during line-transects. Being classified as an occupied nest site was associated with: (1) areas dominated by bedrock canyon and tablelands, shale badlands, sagebrush shrubland, or a mixture of sagebrush shrubland and salt desert scrub; (2) sites between 147 and $6030 \mathrm{~m}$ from an active well; (3) areas with high numbers of lagomorphs; (4) areas with high numbers $(\geq 4)$ of active wells within a $4-\mathrm{km}$ radius of sites; (5) areas with low raptor activity; (6) areas with high numbers of prairie dogs; and (7) areas with high numbers of active wells within a $1.5-\mathrm{km}$ radius of sites.

Both models had misclassification rates that were $41-49 \%$ lower than that of the null models, suggesting that both best trees provided similar levels of model improvement. In addition, both best trees 


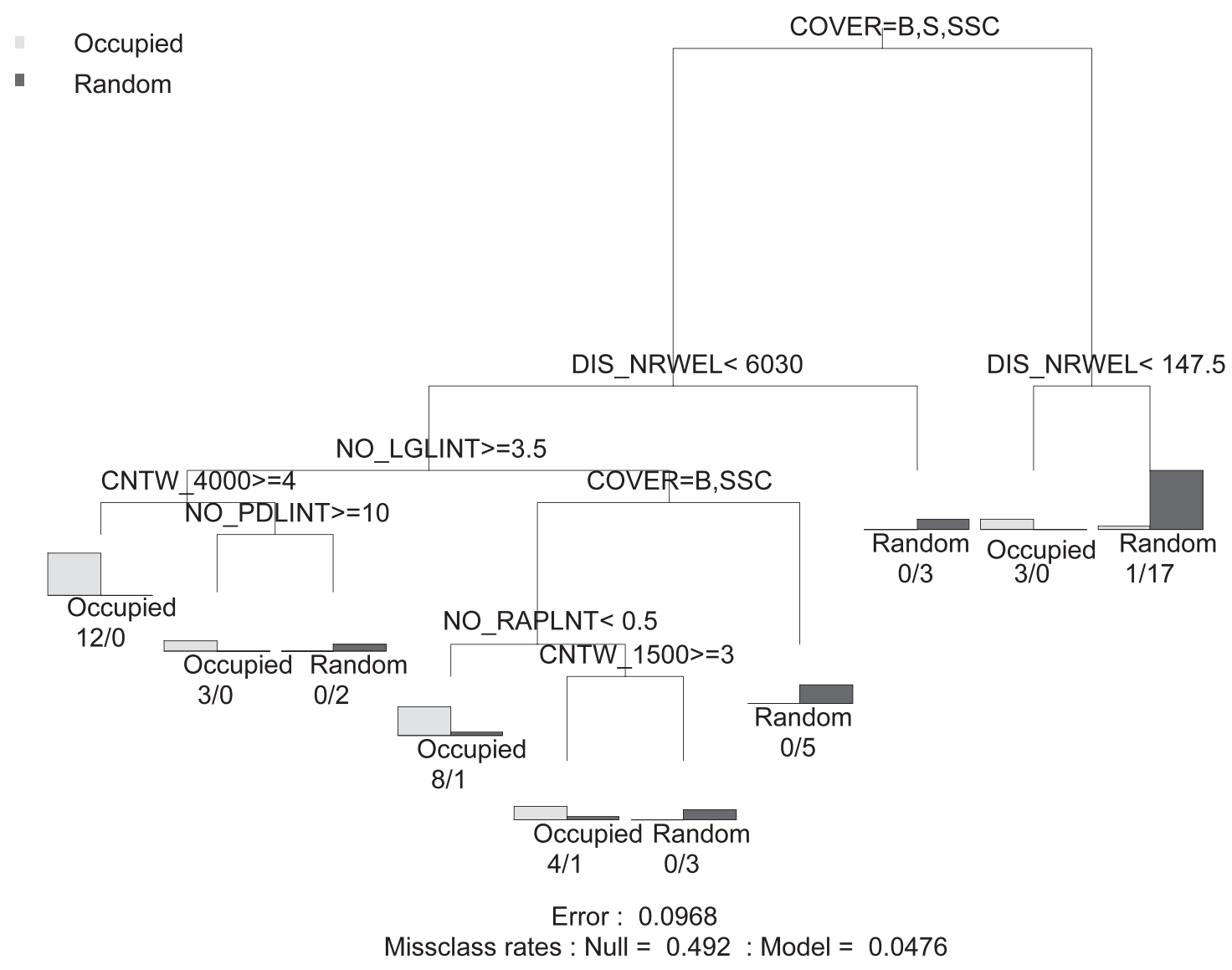

Figure 3. Best classification tree differentiating occupied nests sites of Ferruginous Hawks and randomly selected sites, located within the Uintah Basin, eastern Utah, during three breeding seasons (2002-04). Each of the nine splits is labeled with the explanatory variable that determined the split and its values for sites split to the left (see Table 1 for a definition of abbreviations). For each of the ten leaves, the distribution of the observed classes is shown in a histogram. All abbreviations are explained in Table 1 .

had high $(>80 \%)$ rates of correct classification. Fifty-eight of the 63 observations (31 occupied nest sites and 32 unoccupied historical sites) were correctly classified by the tree differentiating occupied nest sites and unoccupied historical nest sites. The tree differentiating occupied nest sites and random sites correctly classified 60 of the 63 observations (31 occupied nest sites and 32 random sites). Of the 31 occupied nest sites, only one was misclassified by each tree.

Overall, both models indicated that occupied Ferruginous Hawk nest sites were associated with: (1) areas dominated by bedrock canyon and tablelands, or shale badlands, or areas dominated by a mixture of sagebrush shrubland and salt desert scrub; (2) nests located in juniper trees, on cliff ledges, or on rock pinnacles; (3) areas with high numbers of active wells; (4) sites close to active wells; (5) areas with high numbers of lagomorphs and prairie dogs; and (6) sites within $2-3.5 \mathrm{~km}$ of the nearest occupied raptor nest.

\section{DISCUSSION}

The results provided partial support for our predictions (Table 2). We hypothesized that Ferruginous Hawks selected nesting areas in the Uintah Basin with land-cover types that include scattered and isolated juniper trees, higher prey abundance, low numbers of other occupied raptor nests, and low numbers of active wells. We found that only three occupied nests occurred in areas dominated by barren land cover, with the rest occurring in 
Table 2. Predicted and observed associations between the ten potential explanatory variables and being classified as an occupied nest site of Ferruginous Hawks. Predicted associations are based on research hypotheses developed from the literature. Observed associations are based on the values of explanatory variables included in at least one of the best classification trees differentiating between occupied nest sites and unoccupied historical nest sites of Ferruginous Hawks or between occupied nest sites of Ferruginous Hawks and random sites. All sites were located within the Uintah Basin, eastern Utah, during three breeding seasons (2002-04). All abbreviations are explained in Table 1.

\begin{tabular}{ll}
\hline \multicolumn{1}{c}{ PREDICTED ASSOCIATION } & \multicolumn{1}{c}{ OBSERVED ASSOCIATION } \\
\hline NEST_SUB $=$ JUNI, PINN, or MAN; not GROU & NEST_SUB $=$ JUNI, LEDG, or PINN \\
COVER $=$ SSC, S, BS, SBG if S mix, or SJ if not woodland & COVER $=$ B, SSC, or S \\
NO_PDLINT $=$ relatively high abundance & NO_PDLINT $=$ relatively higher abundance \\
NO_LGLINT $=$ relatively high abundance & NO_LGLINT $=$ relatively higher abundance \\
NO_LGRDT $=$ relatively high abundance & NO_LGRDT $=$ no association \\
DIS_NRRAP $=$ relatively large distance to nearest other & DIS_NRRAP $=$ within a threshold distance to nearest other \\
occupied raptor nest & occupied raptor nest \\
NO_RAPLNT = relatively low number of other & NO_RAPLNT $=$ for best tree differentiating occupied and \\
raptors seen & random sites, relatively lower number of other raptors seen \\
CNTR $=$ relatively low number of other occupied & CNTR $=$ no association \\
raptor nests & DIS_NRWEL = relatively smaller distance to nearest active \\
DIS_NRWEL = relatively large distance to nearest & well \\
active well & CNTW $=$ relatively higher number of active wells \\
CNTW $=$ relatively low number of active wells &
\end{tabular}

areas dominated by mixed sagebrush shrubland and salt desert scrub, and sagebrush shrubland land-cover types. Other studies of nesting Ferruginous Hawks reported the importance of habitats with shrub steppe or shrubland mixed with juniper, which provide trees for nesting adjacent to open foraging areas (Olendorff 1993, Dechant et al. 2003).

We found that occupied nests occurred in juniper trees (which was the only tree species in the study area), rock pinnacles (e.g., elevated nest sites), and cliff ledges. Nests in trees and on cliff ledges should provide more protection from mammalian predators, such as coyotes, than other potential nest sites on pinnacles or the ground.

Classification as an occupied nest site of Ferruginous Hawks was also associated with high numbers of prey. This relationship was expected given that previous researchers found positive relationships between Ferruginous Hawk nesting density and prey abundance (Zelenak and Rotella 1997, Ward 2001, Dechant et al. 2003, Schmutz et al. 2008).

Contrary to our predictions, we found no association between being classified as an occupied nest site and the number of occupied nests of conspecific or heterospecific raptors in the vicinity. Schmutz and Hungle (1989) also found habitat selection in Ferruginous Hawks was independent of conspecific or heterospecific hawk nesting density. However, we did find an unexpected association between occupied nest sites and the distance to the closest raptor nest. Rather than being far away from other raptor nests, occupied nests were within 2 to $3.5 \mathrm{~km}$ of the nearest occupied raptor nest. Other studies reported mean nearest neighbor distances between Ferruginous Hawk nests that fall within this optimal range (Lokemoen and Duebbert 1976, Smith and Murphy 1978, Olendorff 1993). This association might be explained if Ferruginous Hawks and other hawk species chose to settle in optimal habitat rather than suboptimal habitat, and additions of new settlers resulted in smaller territories. However, hawks that nest too close to other raptor nests may experience reduced reproductive success due to aggressive interactions such as attacks by neighbors (Schmutz et al. 1980). Thus, Ferruginous Hawks might space themselves sufficiently apart from other occupied raptor nests to reduce competitive interactions and avoid predation from neighboring raptors. As a result, Ferruginous Hawk nests might occur within some optimal distance from other occupied raptor nests.

Although we predicted that occupied nest sites would be associated with low numbers of active wells, the opposite was true: occupied nest sites were associated with higher numbers of active wells. There are several possible explanations for the counterintuitive association between nesting activity and the presence of active wells. The association may be the result of a spurious relationship between the 
occurrence of oil and gas reserves and suitable breeding habitat. Alternatively, a time lag in the response of nesting pairs to development could result in occupied nests occurring closer to active wells and in areas with higher numbers of active wells. Thus, the association may be an artifact of breeding-site fidelity. Another possible explanation is that oil and gas developments may be improving breeding Ferruginous Hawk habitat. Roads and oil pads may result in more diverse habitat mosaics with increased edge habitat. In this semiarid region, vegetation along the edges of oil pads and roads was lush and stayed green longer into the dry summer because it benefits from water running off roads and oil pads. Such habitat alteration might indirectly benefit breeding Ferruginous Hawks by improving the habitat for prairie dogs, jackrabbits, and cottontails. Furthermore, coyotes (Canis latrans) and red foxes (Vulpes vulpes) are wary about foraging near roads and buildings. This may increase prey densities near roads and buildings; it also might reduce the risk of nest depredation for Ferruginous Hawks that nest near them. We did not have adequate data to test this hypothesis in the context of the current study.

Other studies suggest that human development indirectly benefits Ferruginous Hawks. Schmutz (1987), Schmutz and Hungle (1989) and Zelenak and Rotella (1997) reported that in moderately cultivated areas (10-30\%), Ferruginous Hawks had higher nesting densities and greater nest success than in more pristine areas presumably because of greater densities of prey associated with edge habitats. In addition, Zelenak and Rotella (1997) found that the extensive road systems in oil fields were associated with a relatively high numbers of ground squirrel burrows. However, Schmutz (1987) reported that Ferruginous Hawk nesting density had a curvilinear response to cultivation, with nesting density declining when $>30 \%$ of an area was cultivated. If Ferruginous Hawk nesting activity also has a curvilinear response to oil and gas development, beyond some threshold of disturbance intensity, oil and gas development might negatively influence the suitability of breeding habitat. Such a relationship would concur with predictions made by the Intermediate Disturbance Hypothesis (Connell 1978), and Reimer's (1983) findings concerning the response of grassland and forest ecosystems to disturbance.

Overall, our results indicate that Ferruginous Hawks in the Uintah Basin select breeding areas that are mostly dominated by mixed desert shrub habitats that include scattered juniper trees, have a high number of prey, and a high number of active wells. Then Ferruginous Hawks select nest sites in juniper trees, on cliff ledges, or on rock pinnacles. In our study area, these sites are relatively close to the nearest occupied raptor nest. Thus, dominant landcover type, nesting substrate, prey abundance, number of active wells, distances to the closest active well, and distances to the closest other occupied raptor nest are all components of suitable breeding habitat for Ferruginous Hawks in the Uintah Basin.

\section{ACKNOWLEDGMENTS}

Bureau of Land Management (BLM), Utah Division of Wildlife Resources (UDWR), and the Utah Agricultural Experiment Station helped to fund this study. We thank A. Brewerton, B. Johnson, B. Kinkade, P. Kolar, M. Lout, R. Milgalter, and staff from the BLM Vernal Field Office, the UDWR, and Questar Exploration and Production Company which helped conduct fieldwork and provided logistical support. We thank J. Ward, N. Frey, J. Caudell, J. Borgo, S. Coggins, and J. Harrington for their editorial help. This paper was approved as Utah Agricultural Experiment Station paper 8401 .

\section{Literature Cited}

AyERs, L.W. AND S.H. ANDERSON. 1999. An aerial sightability model for estimating Ferruginous Hawk population size. Journal of Wildlife Management 63:85-97.

Bechard, M.J., R.L. Knight, D.G. SMith, ANd R.E. Fitzner. 1990. Nest sites and habitats of sympatric hawks (Buteo spp.) in Washington. Journal of Field Ormithology 61:159-170.

- AND J.K. SchmutZ. 1995. Ferruginous Hawk (Buteo regalis). In A. Poole and F. Gill [EDs.], The birds of North America, No. 172. The Academy of Natural Sciences, Philadelphia, PA and the American Ornithologists' Union, Washington, DC U.S.A.

Bureau of Land Management (BLM). 2005. Shape file map of oil and gas wells in Utah. Bureau of Land Management, Utah State Office, Salt Lake City, UT U.S.A.

ConNell, J.H. 1978. Diversity in tropical rain forests and coral reefs. Science 199:1302-1310.

DE’ATH, G. 2004. Mvpart: multivariate partitioning. Extensions and adaptations of rpart to mvpart. Mvpart package version 1.0-1. http://cran.stat.ucla.edu/ (last accessed 17 July 2012).

- AND K.E. FABRICIUS. 2000. Classification and regression trees: a powerful yet simple technique for ecological data analysis. Ecology 81:3178-3192.

Dechant, J.A., M.L. Sondreal, D.H. Johnson, L.D. IgL, C.M. Goldade, A.L. Zimmerman, and B.R. Euliss. 2003. Effects of management practices on grassland birds: Ferruginous Hawk. Northern Prairie Wildlife Research Center, Jamestown, ND U.S.A. http://www.npwrc. usgs.gov/resource/literatr/grasbird/feha/feha.htm (last accessed 17 July 2012). 
FyFe, R.W. AND R.R. OlEndorfF. 1976. Minimizing the dangers of nesting studies to raptors and other sensitive species. Canadian Wildlife Service, Environment Canada, Occasional Paper Number 23, Ottawa, ON, Canada.

Gilmer, D.S. AND R.E. STEWART. 1983. Ferruginous Hawk populations and habitat use in North Dakota. Journal of Wildlife Management 47:146-157.

Giovanni, M.D., C.W. Boal, And H.A. Whitlaw. 2007. Prey composition and provisioning by breeding Ferruginous Hawks and Swainson's Hawks on the southern Great Plains, USA. Wilson Journal of Ornithology 119:558-569.

KeEley, W.H. 2009. Diet and behavior of Ferruginous Hawks nesting in two grasslands in New Mexico with differing anthropogenic alteration. M.S. thesis, Boise State Univ., Boise, ID U.S.A.

- AND M.J. BECHARD. 2011. Flushing distances of Ferruginous Hawks nesting in rural and exurban New Mexico. Journal of Wildlife Management 75:1034-1039.

KeOugh, H.L. 2006. Factors influencing breeding Ferruginous Hawks (Buteo regalis) in the Uintah Basin, Utah. Ph.D. dissertation, Utah State Univ., Logan, UT U.S.A.

LeAry, A.W., R. MAZAikA, AND M.J. Bechard. 1998. Factors affecting the sizes of Ferruginous Hawk home ranges. Wilson Bulletin 110:198-205.

LeSLIE, D.G. 1992. Population status, habitat and nest-site characteristics of a raptor community in eastern Colorado. M.S. thesis, Colorado State Univ., Fort Collins, CO U.S.A.

Lokemoen, J.T. And H.F. Duebbert. 1976. Ferruginous Hawk nesting ecology and raptor populations in northern South Dakota. Condor 78:464-470.

Morrison, M.L., W.M. Block, M.D. StRickland, AND W.L. KENDALL. 2001. Wildlife study design. Springer-Verlag, New York, NY U.S.A.

OlENDORFF, R.R. 1993. Status, biology, and management of Ferruginous Hawks: a review. Raptor Research and Technical Assistance Center, Special Report. USDI Bureau of Land Management, Boise, ID U.S.A.

R Development Core Team. 2005. R: a language and environment for statistical computing. R Foundation for Statistical Computing, Vienna, Austria. http://www.Rproject.org (last accessed 7 July 2012).

ReImer, W.A. 1983. Disturbance and basic properties of ecosystem energetics. Pages 83-98 in H.A. Mooney and M. Godron [EDS.], Disturbance and ecosystems. Springer-Verlag, New York, NY U.S.A.
Rosamonde, R.C., J.E. Cartron, and P.J. Polechla, JR. 2003. The importance of prairie dogs to nesting Ferruginous Hawks in grassland ecosystems. Wildlife Society Bulletin 31:1073-1082.

SchmuTZ, J.K. 1987. The effect of agriculture on Ferruginous and Swainson's hawks. Journal of Range Management 40:438-440.

, D.T.T. FlockHARD, C.S. Houston, ANd P.D. MCLOUghLIN. 2008. Demography of Ferruginous Hawks breeding in western Canada. Journal of Wildlife Management 72: 1352-1360.

— AND D.J. Hungle. 1989. Population of Ferruginous and Swainson's hawks increase in synchrony with ground squirrels. Canadian Journal of Zoology 67:2596-2601.

— S.M. SchmutZ, AND D.A. BoAg. 1980. Coexistence of three species of hawks (Buteo spp.) in the prairieparkland ecotone. Canadian Journal of Zoology 58: 1075-1089.

Smith, D.G. And J.R. Murphy. 1978. Biology of the Ferruginous Hawk in central Utah. Sociobiology 3:79-95.

Stalmaster, M.V. 1988. Ferruginous Hawk nesting mitigation study: final report. ERO Resources Corporation, Denver, CO U.S.A.

USGS National Gap Analysis Program. 2004. Provisional digital land cover map for the Southwestern United States. Version 1.0. Remote Sensing and Geographical Information Systems Laboratory, College of Natural Resources, Utah State Univ., Logan, UT U.S.A.

VAN HoRn, R.C. 1993. Ferruginous Hawk and Prairie Falcon reproductive and behavioral responses to human activity near Kevin Rim, Montana. M.S. thesis, Montana State Univ., Bozeman, MT U.S.A.

WARD, J.M. 2001. Avian assessment of risks: balancing the threat of starvation and predation during reproduction. Ph.D. dissertation, Utah State Univ., Logan, UT U.S.A.

White, C.M. And T.L. Thurow. 1985. Reproduction of Ferruginous Hawks exposed to controlled disturbance. Condor 87:14-22.

ZeLENAK, J.R. AND J.J. Rotella. 1997. Nest success and productivity of Ferruginous Hawks in northern Montana. Canadian Journal of Zoology 75:1035-1041.

Received 29 January 2012; accepted 27 July 2012 